\title{
O legado das teorias lexicológicas tradicionais para a práxis lexicográfica: uma discussão sobre a metalinguagem da definição (com ênfase nos dicionários de língua espanhola)
}

\section{The legacy of traditional lexicological theories to lexicographic praxis: a discussion on the metalanguage of definitions (with special attention to Spanish dictionaries)}

\section{Virginia Sita Farias}

Universidade Federal do Rio de Janeiro, Cidade do Rio de Janeiro, Rio de Janeiro, Brasil virginiafarias@hotmail.com

Resumo: As teorias lexicológicas tradicionais costumam classificar as palavras em "expressões com significado" e "expressões sem significado" com base na distinção entre "significado lexical" e "significado categorial". No âmbito (meta)lexicográfico, a oposição entre "expressões com significado" e "expressões sem significado" redunda na distinção entre metalinguagem de conteúdo/de segundo enunciado e metalinguagem de signo/de primeiro enunciado. O objetivo deste trabalho é demonstrar a insustentabilidade de uma oposição estrita entre "expressões com significado" e "expressões sem significado" e avaliar as consequências disso na seleção da metalinguagem a ser empregada na redação das paráfrases explanatórias.

Palavras-chave: (meta)lexicografia; definição lexicográfica; metalinguagem; significado.

Abstract: The traditional theories of lexicology classify the words into "meaningful" and "meaningless expressions", according to the distinction between "lexical meaning" and "categorial meaning". Where (meta) lexicography is concerned, the opposition between "meaningful" and "meaningless expressions" results in a distinction between "metalanguage 
of content" and "metalanguage of sign". The aim of this paper is to demonstrate that an opposition between "meaningful" and "meaningless expressions" stricto sensu does not hold, and to evaluate its consequences for the selection of the metalanguage that should be used to write the explanatory paraphrases.

Keywords: (meta)lexicography; lexicografic definition; metalanguage; meaning.

Recebido em 29 de agosto de 2014. Aprovado em 09 de outubro de 2014.

\section{Introdução}

Definir o que se deve entender por significado é uma das tarefas mais árduas que corresponde aos linguistas, de modo geral, e aos semanticistas, de modo mais específico. A (ausência de uma) definição de significado, por sua vez, afeta diretamente a prática lexicográfica, em especial a redação das paráfrases definidoras. O problema torna-se patente mediante a revisão da literatura relativa ao tema, tanto no âmbito da semântica (p. ex., OGDEN; RICHARDS, 1956; ULLMANN, 1964; GREIMAS, 2007; POTTIER, 1974; LYONS, 1989; COSERIU, 2004, 1995) quanto no âmbito de aplicação ao fazer lexicográfico (p. ex., HILTY, 1988, 1995, 1997; KILGARRIFF, 1997, 2007; GEERAERTS, 2001, 2003; SINCLAIR, 2004; ATKINS; RUNDELL, 2008; BUGUEÑO MIRANDA; FARIAS, 2011b; 2013a; 2013b; FARIAS, 2013).

O problema relativo à definição de significado encontra, ainda, outros desdobramentos. No âmbito dos estudos de lexicologia e semântica lexical de base estruturalista, é recorrente a evocação da oposição entre significado lexical e significado categorial. É, pois, com fundamento nessa oposição que se costuma estabelecer uma distinção entre o que aqui - recorrendo à terminologia empregada em Bugueño Miranda e Farias (2011a) - designamos como "expressões com significado" e "expressões sem significado".

A respeito dessa terminologia, Bugueño Miranda e Farias (2011a) esclarecem que: 
o dicionário lematiza todas aquelas unidades em que se explica a relação entre o significante léxico (que, no plano lexicográfico, está representado pelo signo-lema) e seu conteúdo (representado pelo comentário semântico). Esta distinção, no entanto, é insuficiente, porque a natureza do "conteúdo" [...] é muito mais complexa, já que, claramente, há palavras que "não significam" nada, mas que parecem ajudar a estabelecer relações de significação. É justamente por isso que a linguística estabeleceu uma relação entre palavras "que significam" e palavras "que não significam". (BUGUEÑO MIRANDA; FARIAS, 2011a, p. 20) ${ }^{1}$

Estamos conscientes - e não é nossa intenção de forma alguma sonegar esta informação - de que aquilo que aqui se designa como "expressões com significado" e "expressões sem significado" recebe, na literatura correspondente, uma série de designações tão variadas quanto os critérios utilizados para definir ambos os fenômenos ${ }^{2}$. Entretanto, o que subjaz a todas as propostas de classificação das palavras e, consequentemente, de adequação terminológica - como a citação de

${ }^{1}$ No original: "el diccionario lematiza todas aquellas unidades donde se explica la relación entre el significante léxico (que, en el plano lexicográfico, está representado por el signo-lema) y su contenido (representado por el comentario semántico). Esta distinción, sin embargo, es insuficiente, porque la naturaleza del «contenido» [...] es mucho más compleja, ya que hay claramente palabras que «no significan» nada, sino que parecen ayudar a establecer relaciones de significación. Es justamente por ello, que la lingüística ha establecido una distinción entre palabras «que significan» y palabras «que no significan»".

${ }^{2}$ A esse respeito, cf. a seção 2. Entre as designações mais recorrentes na literatura especializada, mencionamos palavras lexicais, palavras lexemáticas, content words, full words, lexical words, Autosemantika, Kategorema, kategorematische Ausdrücke, no primeiro caso, e palavras gramaticais, palavras categoremáticas, form words, function words, grammatical words, Synsemantika, Synkategorema, synkategorematische Ausdrücke, no segundo caso (LUTZEIER, 1985; HAUSMANN, 1995; MATTHEWS, 1997 , s.v. form word; s.v. function word; s.v. grammatical word; s.v. content word; s.v. lexical word; BUSSMANN, 2008, s.v. Autosemantikum; s.v. Synsemantikum; GLÜCK, 2010, s.v. Autosemantikum; s.v. Synsemantikon). Esclarece-se que, nas citações de dicionários de linguística, emprega-se a sigla s.v. - sub voce "sob o lema" - para indicar o verbete consultado; já nas citações de dicionários de língua, por sua vez, emprega-se igualmente a sigla s.v. para indicar o verbete consultado, bem como a sigla $a c$. - "acepção" - para indicar a acepção no interior do verbete à qual se faz referência. 
Bugueño Miranda e Farias (2011a) transcrita ad supra procura evidenciar - é a oposição entre palavras providas de conteúdo semântico "autônomo" (ou "expressões com significado") e palavras desprovidas de conteúdo semântico "autônomo", cuja função é estabelecer relações entre as palavras com conteúdo semântico (ou "expressões sem significado").

Já no âmbito estritamente (meta)lexicográfico, no que concerne à redação das paráfrases explanatórias, procurou-se estabelecer uma relação entre "palavras com significado" e metalinguagem de conteúdo/ de segundo enunciado, por um lado, e entre "palavras sem significado" e metalinguagem de signo/de primeiro enunciado, por outro. Essa relação, evidentemente, na prática, nem sempre se revela factível.

Este trabalho tem, portanto, um duplo objetivo: (a) do ponto de vista puramente lexicológico, demonstrar - corroborando os resultados obtidos anteriormente em Bugueño Miranda e Farias (2011a) - a insustentabilidade de uma oposição estrita entre "palavras com significado" e "palavras sem significado"; e (b) do ponto de vista (meta) lexicográfico, avaliar as consequências da insustentabilidade dessa distinção para a prática definitória, mediante a análise de paráfrases definidoras extraídas de dicionários de língua espanhola.

\section{Discussão acerca da dicotomia significado lexical / significado categorial}

Coseriu (1978), ao propor os fundamentos da sua teoria lexemática, distingue cinco tipos de significado:

(a) Significado lexical: corresponde ao conteúdo semântico da unidade léxica.

(b) Significado categorial: indica a classe de palavras à qual pertence a unidade léxica.

(c) Significado instrumental: corresponde ao valor de cada um dos morfemas que constituem as unidades léxicas.

(d) Significado sintático: corresponde ao valor atribuído às construções gramaticais.

(e) Significado ôntico: corresponde ao valor intencionalmente atribuído ao acontecimento descrito em uma proposição, podendo ser afirmativo, negativo, interrogativo ou imperativo. 
Lutzeier (1985, p. 21) sustenta que o significado lexical e o significado categorial - ou significado nocional (Begriffsbedeutung) e significado relacional (Beziehungsbedeutung), respectivamente constituem os dois principais tipos de significado. Fundamentadas nessa distinção, as teorias lexicológicas tradicionais costumam estabelecer uma oposição entre as expressões linguísticas que apresentam significado lexical e categorial - que fazemos corresponder às "expressões com significado" - e as expressões linguísticas que apresentam tão somente significado categorial - que, por sua vez, fazemos corresponder às "expressões sem significado".

Se se considera que o significado lexical corresponde ao conteúdo semântico propriamente dito, ao passo que o significado categorial refere-se apenas à categoria morfológica à qual pertence a unidade léxica, assume-se, consequente e forçosamente, que há palavras que não têm conteúdo semântico ou "não significam", mas simplesmente ajudam a estabelecer relações entre as palavras que têm conteúdo semântico ou "significam". Bußmann (2008, s.v. Autosemantikum), no entanto, adverte que essa distinção é insustentável. É tal a dificuldade de se defender uma oposição estrita entre "expressões com significado" e "expressões sem significado", que não existe sequer um consenso em relação à conceituação de ambos os fenômenos:

Quadro 1 - "Expressões com significado" versus "expressões sem significado"

\begin{tabular}{|c|c|c|}
\hline & $\begin{array}{l}\text { "Expressões com } \\
\text { significado" }\end{array}$ & $\begin{array}{l}\text { "Expressões sem } \\
\text { significado" }\end{array}$ \\
\hline Zgusta (1971) & $\begin{array}{l}\text { Palavras que contêm } \\
\text { significado lexical; } \\
\text { express oxes que } \\
\text { apontam para o mundo } \\
\text { extralinguístico, } \\
\text { realizando funçós } \\
\text { designativas. Por } \\
\text { exemplo: substantivos, } \\
\text { verbos. }\end{array}$ & $\begin{array}{l}\text { Palavras que realizam } \\
\text { funções gramaticais. Por } \\
\text { exemplo: preposições, } \\
\text { conjun çôes, verbos } \\
\text { auxiliares etc. }\end{array}$ \\
\hline Lutzeier (1985) & $\begin{array}{l}\text { Palavras que contêm } \\
\text { significado nocional. } \\
\text { Por exemplo: verbos, } \\
\text { substantivos, adjetivos } \\
\text { (tradicionalmente). }\end{array}$ & $\begin{array}{l}\text { Palavras que contêm } \\
\text { significado relacional. Por } \\
\text { exemplo: demais classes } \\
\text { de palavras, verb o } \\
\text { modais e auxiliares. }\end{array}$ \\
\hline
\end{tabular}




\begin{tabular}{|c|c|c|}
\hline Matthews (1997) & $\begin{array}{l}\text { Palavras que possuem } \\
\text { significado lexical. Por } \\
\text { exemplo: substantivos, } \\
\text { verbos. }\end{array}$ & $\begin{array}{l}\text { Palavras que possuem } \\
\text { significado gramatical. } \\
\text { Por exemplo: artigos, } \\
\text { pronomes, preposições. }\end{array}$ \\
\hline Palmer (2001) & $\begin{array}{l}\text { Palavras cujo significado } \\
\text { se esperaria encontrar } \\
\text { em um dicionário. Por } \\
\text { exemplo: substantivos, } \\
\text { verbos, adjetivos, } \\
\text { advérbios. }\end{array}$ & $\begin{array}{l}\text { Palavras que possuem } \\
\text { apenas significado } \\
\text { gramatical, que não pode } \\
\text { ser obtido isoladamente, } \\
\text { mas apenas em relação } \\
\text { a outras palavras ou à } \\
\text { sentença inteira. } \\
\text { Por exemplo: pronomes, } \\
\text { artigos, preposições, } \\
\text { conjunções. }\end{array}$ \\
\hline Crystal (2001) & $\begin{array}{l}\text { Palavras que contêm } \\
\text { um significado lexical } \\
\text { estável. Por exemplo: } \\
\text { substantivos, adjetivos, } \\
\text { verbos. }\end{array}$ & $\begin{array}{l}\text { Palavras que não contêm } \\
\text { significado lexical, e } \\
\text { cuja função é expressar } \\
\text { uma relação gramatical. } \\
\text { Por exemplo: artigos, } \\
\text { preposições, conjunções. }\end{array}$ \\
\hline $\begin{array}{l}\text { Hartmann e James } \\
\text { (2001) }\end{array}$ & $\begin{array}{l}\text { Palavras com significado } \\
\text { predominantemente } \\
\text { lexical. Por exemplo:: } \\
\text { substantivos, verbos, } \\
\text { adjetivos. }\end{array}$ & $\begin{array}{l}\text { Palavras que têm um papel } \\
\text { gramatical na sentença. } \\
\text { Por exemplo: artigos, } \\
\text { conjunções, preposições. }\end{array}$ \\
\hline Ulrich (2002) & $\begin{array}{l}\text { Palavras com significado } \\
\text { lexical autônomo, isto é, } \\
\text { independente do contexto, } \\
\text { e que podem desempenhar } \\
\text { o papel de núcleo do } \\
\text { sintagma. Por exemplo: } \\
\text { substantivos, verbos, } \\
\text { adjetivos, advérbios. }\end{array}$ & $\begin{array}{l}\text { Palavras que não dispõem } \\
\text { de significado autônomo: } \\
\text { o significado é, em grande } \\
\text { parte, dependentedo contexto. } \\
\text { Por exemplo: pronomes, } \\
\text { preposições, artigos. }\end{array}$ \\
\hline Borba (2003) & $\begin{array}{l}\text { Palavras que relacionam } \\
\text { o sistema de noções da } \\
\text { língua com o mundo } \\
\text { exterior, ou sej a, } \\
\text { representam a realidade } \\
\text { extralinguística. Podem } \\
\text { representar substâncias } \\
\text { (substantivos), atributos } \\
\text { ou qualidades (adjetivos), } \\
\text { a ções, estados ou } \\
\text { processos (verbos). }\end{array}$ & $\begin{array}{l}\text { Palavras que constituem } \\
\text { um sistema de noções que } \\
\text { se realizam no interior } \\
\text { do sistema. Podem } \\
\text { indicar quantificação } \\
\text { e inten s i f i a ção, } \\
\text { relações espaciais e } \\
\text { temporais, referenciação, } \\
\text { mostração, identificação, } \\
\text { modalização etc. }\end{array}$ \\
\hline
\end{tabular}




\begin{tabular}{|c|c|c|}
\hline Bechara (2006) & $\begin{array}{l}\text { Palavras que apresentam } \\
\text { significado lexical e } \\
\text { categorial. Por exemplo: } \\
\text { substantivos, adjetivos, } \\
\text { verbos, advérbios. }\end{array}$ & $\begin{array}{l}\text { Palavras categoremáticas: } \\
\text { Apres entam a e nas } \\
\text { significado categorial, } \\
\text { sem representar nenhuma } \\
\text { matéria extralinguística. } \\
\text { Por exemplo: pronomes, } \\
\text { numerais. } \\
\text { Palavras morfemáticas: } \\
\text { Apres entam a penas } \\
\text { significado instrumental. } \\
\text { Por exemplo: artigo, } \\
\text { preposição, conjunção. }\end{array}$ \\
\hline Bußmann (2008) & $\begin{array}{l}\text { Palavras que contêm } \\
\text { um significado lexical } \\
\text { autônomo, independente } \\
\text { do contexto. Por exemplo: } \\
\text { substantivos, verbos e } \\
\text { adjetivos. }\end{array}$ & $\begin{array}{l}\text { P a lav a q u e } \\
\text { (supostamente), e m } \\
\text { ocorrência isolada, não } \\
\text { carregam significado } \\
\text { lexical autônomo. } \\
\text { Também expressões } \\
\text { linguísticas polissêmicas, } \\
\text { que apresentam aspectos } \\
\text { diferentes do significado } \\
\text { conforme o contexto. Por } \\
\text { exemplo: unidades léxicas } \\
\text { que formam classes mais } \\
\text { ou menos fechadas, } \\
\text { adjetivos relacionais. }\end{array}$ \\
\hline Glück (2010) & $\begin{array}{l}\text { Lexemas que possuem } \\
\text { um significado lexical } \\
\text { autônomo, independente } \\
\text { do contexto, e que podem } \\
\text { funcionar como núcleo do } \\
\text { sintagma. Por exemplo: } \\
\text { substantivos, verbos, } \\
\text { adjetivos, advérbios. }\end{array}$ & $\begin{array}{l}\text { Lexemas aos quais, } \\
\text { às vezes, se combina } \\
\text { um significado lexical } \\
\text { autônomo e que não } \\
\text { podem atuar como núcleo } \\
\text { do sintagma. Por exemplo: } \\
\text { artigos, conjunções, } \\
\text { preposições. }\end{array}$ \\
\hline
\end{tabular}

É possível constatar que os critérios utilizados na classificação das expressões linguísticas, em alguns casos, sobrepõem-se uns aos outros, e, em outros, são completamente divergentes. Sumariamente, os critérios de classificação empregados são os seguintes:

(a) oposição entre significado lexical e significado categorial (ZGUSTA, 1971; LUTZEIER, 1985; MATTHEWS, 1997; PALMER, 2001; CRYSTAL, 2001; HARTMANN; JAMES, 2001; BECHARA, 2006); 
(b) oposição entre palavras com significado léxico autônomo (independente de um contexto) e sem significado léxico autônomo (dependente de um contexto) (BUSSMANN, 2008; GLÜCK, 2010; ULRICH, 2002);

(c) oposição entre palavras que podem constituir núcleo de sintagma e palavras que não podem constituir núcleo de sintagma (GLÜCK, 2010; ULRICH, 2002);

(d) oposição entre palavras que relacionam a língua com a realidade extralinguística e palavras que relacionam a língua com ela mesma (ZGUSTA, 1971; BORBA, 2003).

A análise das classificações propostas demonstra que a maioria dos autores concorda que os substantivos, verbos e adjetivos seriam fortes candidatos a "expressões com significado". Não obstante, Lutzeier (1985) recorda o fato de que o Duden, Das große Wörterbuch der deutschen Sprache, em sua edição de 1984, incluía, entre as "expressões sem significado", os verbos modais e auxiliares. Essa é, igualmente, a posição de Glück (2010, s.v. Synsemantikon), que considera como "expressões sem significado" as que pertencem às classes fechadas, como artigos, conjunções, preposições e verbos auxiliares. Bußmann (2008, s.v. Synsemantikum), por outro lado, enfatiza que "Synsemantika lato sensu" são "expressões linguísticas polissêmicas, como o adjetivo bom/boa, que apresenta diferentes aspectos do significado, de acordo com o contexto, cf. A resposta é boa/? seu caráter é bom/o tempo está bom/a comida está boa"3.

Por fim, a classe dos advérbios é a que parece menos consensual. Glück (2010) e Ulrich (2002), por exemplo, mencionam os advérbios entre as "expressões com significado". Bußmann (2008), assim como a maioria dos autores, não menciona os advérbios em nenhum dos grupos. Borba (2003, p. 46), entretanto, define as palavras gramaticais como unidades léxicas que podem "indicar quantificação e intensificação, relações espaciais e temporais, referenciação, mostração, identificação, modalização etc.". Uma definição tão ampla e carente de precisão poderia respaldar, até mesmo, a inclusão dos advérbios entre as palavras gramaticais.

No sentido contrário, a discussão realizada em Bugueño Miranda e Farias (2011a) sugere que algumas unidades léxicas tradicionalmente

\footnotetext{
${ }^{3}$ No original: "polyseme sprachliche Ausdrücke wie das Adjektive gut, das je nach Kontext unterschiedliche Bedeutungsaspekte aufweist, vgl. Die Antwort/sein Charakter/ das Wetter/das Essen ist gut".
} 
classificadas no grupo das "expressões sem significado" poderiam, sim, apresentar conteúdo semântico. Partindo-se da afirmação de Schifko (1992, p. 141-142), segundo a qual o emprego de sinônimos somente é possível nos casos em que há "identidade de significado" (identidad de significado $)^{4}$, assumiu-se a sinonímia como um recurso viável para a comprovação da existência de um "conteúdo semântico".

A identidade de significado pode ser expressa em termos de uma proposição, que, por sua vez, constituiria o tertium comparationis da relação sinonímica. A título de ilustração, propõe-se comparar as sentenças No dijo a qué vino e No dijo para qué vino. O tertium comparationis entre as preposições $a$ e para em ambas as sentenças, respectivamente, é "com que finalidade". De acordo com o proposto em Bugueño Miranda e Farias (2011a), comprovar-se-ia, dessa forma, a existência de um "conteúdo semântico". Diante dos argumentos arrolados, as classificações tradicionais das expressões linguísticas sintetizadas no Quadro 1 perderiam sustentação.

Para finalizar a discussão, convém recordar que há uma carência de estudos sobre a natureza dos próprios signos linguísticos, o que é essencial para que se possa passar, no âmbito da lexicografia, à descrição do seu (suposto) "conteúdo semântico". Bugueño Miranda e Farias (2011a) concluem que uma abordagem que busque definir o que é "conteúdo semântico" ou "significado" de uma unidade léxica não oferece resultados completamente satisfatórios; para tanto, é necessário recorrer a expedientes metodológicos indiretos (por exemplo, a sinonímia), a fim de propor uma aproximação ao problema nuclear.

\footnotetext{
${ }^{4}$ Schifko (1992, p. 141-142) reconhece, no entanto, que "efetivamente, há bem poucos sememas que coincidem em todos os aspectos (denotação, conotação, frequência, distribuição)" [efectivamente, hay muy contados sememas que coinciden en todos los aspectos (denotación, connotación, frecuencia, distribución)], de modo que "se deve limitar a identidade aos aspectos denotativo e cognitivo, porque, em geral, quando dois sememas designam a mesma classe de referentes, variam em outros aspectos" [hay que limitar la identidad al aspecto denotativo y cognitivo, porque, en general, cuando dos sememas designan la misma clase de referentes, varían en otros aspectos]. Este seria o caso, em espanhol, das designações pendejo, boludo, pelotudo y huevón para "[pessoa] pouco inteligente", que estão marcadas diatópica e diastraticamente. Frente a isso, sugerese substituir "identidade de significado" (identidad de significado) por "similaridade de significado" (Bedeutungsähnlichkeit) (BUSSMANN, 2008, s.v. Synonymie).
} 


\section{A oposição significado lexical / significado categorial e seu reflexo na práxis lexicográfica}

A tradição (meta)lexicográfica hispânica, fortemente influenciada pela francesa, costuma estabelecer uma distinção entre metalinguagem de conteúdo/de segundo enunciado e metalinguagem de signo/de primeiro enunciado ${ }^{5}$. As paráfrases em metalinguagem de conteúdo, ou definições próprias, respeitam o princípio de identidade de categoria morfológica e admitem submeter-se à prova da substituição; por exemplo: volada "Vuelo hecho de una vez" (DUEe, 2001, s.v. volada). As paráfrases em metalinguagem de signo, definições impróprias ou explicações, por outro lado, aparecem normalmente introduzidas por fórmulas definitórias que inviabilizam sua submissão à prova da substituição; por exemplo: vox populi "Expresión latina que significa literalmente «voz del pueblo», con que se alude a lo que la gente dice en general comentando cierta cosa" (DUEe, 2001, s.v. vox populi). No que concerne à práxis lexicográfica, portanto, a oposição entre significado lexical e significado categorial afeta, em última instância, justamente um dos princípios basilares da redação de paráfrases definidoras, ou seja, a universalidade da lei da sinonímia, segundo a qual a definição deve poder substituir o signo-lema em qualquer contexto, sem que haja alteração de sentido do enunciado ${ }^{6}$.

\footnotetext{
${ }^{5}$ Sobre o tratamento da metalinguagem da definição na tradição (meta)lexicográfica hispânica, cf. Seco (2003), Porto Dapena (2000) e Martínez de Souza (2009); sobre o tratamento da metalinguagem da definição na tradição (meta)lexicográfica francesa, cf. Rey-Debove (1971; 1989).

"Seco (2003, p. 32) assegura que "a comutabilidade é o banco de provas da definição" [la sustituibilidad es el banco de pruebas de la definición]. Canellada (1988, p. 130), por sua vez, corrobora essa afirmação: "[A] lei da comutabilidade é a que prova definitivamente a validez de uma definição" [La ley de la sustituibilidad es la que prueba definitivamente la validez de una definición]. A esse respeito, no entanto, Weinreich (1967, p. 39) já expressava uma opinião fundamentalmente contrária à anterior, argumentando que os dicionários estão restringidos pelo fato de que "a definição deve ser um sintagma endocêntrico, sujeito aos papéis sintáticos correntes da língua-objeto, um sintagma funcionalmente equivalente aos termos definidos. [...] Essa convenção, embora favoreça a elegância, parece convir à demanda de intermutabilidade entre o termo e sua definição, o que é irrisório em se tratando de línguas naturais" [the definition must be an endocentric phrase, subject to the rules of ordinary object-language syntax, a phrase functionally equivalent to the defined terms. [...] This convention, though conducive to elegance, seems due to a claim of interchangeability between the term and its definition, which is preposterous for natural languages].
} 
Seco (2003, p. 33-34), levando em consideração a distinção entre metalinguagem de conteúdo e metalinguagem de signo, estabelece uma oposição entre "palavras definíveis" - às quais corresponderiam as definições próprias - e "palavras indefiníveis" - às quais, por sua vez, corresponderiam as definições impróprias ${ }^{7}$. Em outros termos: as "expressões com significado" (entre as quais, incluem-se, tradicionalmente, os substantivos, adjetivos, verbos e, em parte, também os advérbios) definir-se-iam em metalinguagem de conteúdo, ao passo que as "expressões sem significado" (representadas, também tradicionalmente, pelas demais classes de palavras) deveriam definir-se tão somente em metalinguagem de signo.

A oposição "palavras definíveis" / "palavras indefiníveis", no entanto, diante do exposto na seção anterior, deve ser posta em xeque - o que não afeta absolutamente a distinção entre metalinguagem de signo e metalinguagem de conteúdo, aliás, extremamente útil para a prática lexicográfica ${ }^{8}$. Apresentamos, a seguir, dois argumentos em favor da refutação da oposição "palavras definíveis" / "palavras indefiníveis" proposta em Seco (2003).

Em primeiro lugar, a discussão sintetizada na seção anterior deixou claro que não é possível sustentar uma distinção stricto sensu entre "expressões com significado" e "expressões sem significado". Em relação à tarefa de elaborar as definições, por sua vez, a insustentabilidade da distinção proposta no âmbito das teorias lexicológicas tradicionais reflete-se em que nem sempre as palavras que, presumidamente, "significam" se deixam definir por metalinguagem de conteúdo", e, por outro lado, as palavras das quais se diz, normalmente, que "não significam", podem, em muitos casos, definir-se mediante uma paráfrase em metalinguagem de conteúdo ${ }^{10}$.

\footnotetext{
${ }^{7}$ Neste trabalho, fazemos corresponder as noções de "palavras definíveis" e "palavras indefiníveis", respectivamente, às noções de "expressões com significado" e "expressões sem significado".

${ }^{8}$ Sobre a relevância da distinção entre metalinguagem de conteúdo e metalinguagem de signo para a (meta)lexicografia e sua aplicação no âmbito de uma teoria da definição lexicográfica, cf. Bugueño Miranda (2009) e Farias (2013, p.197-219).

${ }^{9}$ Exemplos de "palavras com significado", para as quais a solução mais eficiente seria uma definição em metalinguagem de signo, são os adjetivos relacionais. Por exemplo: vocal "De [la] voz: 'Concierto vocal. Cuerdas vocales"' (DUEe, 2001, s.v. vocal, ac.1). ${ }^{10}$ Há preposições e conjunções para as quais, muitas vezes, é possível apresentar definições em metalinguagem de conteúdo. Por exemplo.: hacia "Alrededor de, cerca de. Hacia las
} 
Assim, pois, o âmbito de aplicação de cada uma das metalinguagens não será tão estrito.

Em segundo lugar, a oposição entre "palavras definíveis" e "indefiníveis" supõe a existência de um grupo fixo de palavras/expressões que se deixam definir mediante metalinguagem de conteúdo (as "palavras/ expressões definíveis") e outro grupo fixo de palavras/expressões que não se deixam definir mediante metalinguagem de conteúdo (as "palavras/expressões indefiníveis"). Essa oposição, contudo, acarreta dois problemas. Por um lado, sabemos, em função do exposto no tópico anterior, que não se pode estabelecer aprioristicamente um conjunto de palavras às quais convém uma "definição" propriamente dita, oposto a outro conjunto de palavras às que convém uma "explicação". Por outro lado, e, talvez, o mais grave, ao estabelecer-se a oposição entre palavras "definíveis" e "indefiníveis", não se explica o que se deve entender por indefinivel. Supondo, no entanto - e, de fato, isto procede -, que Seco (2003) fundamenta essa oposição na clássica distinção entre significado lexical e significado categorial, de forma que se considerariam "palavras indefiníveis" as que apresentassem apenas significado categorial, e que, portanto, aceitariam apenas definições em metalinguagem de signo, voltaríamos à questão anterior. Isso significa que nos encontramos diante de uma espécie de círculo vicioso.

Deve-se levar em conta, por um lado, que existem "palavras/ expressões com significado" que se definem com mais propriedade mediante metalinguagem de signo. Comparemos, a título de ilustração, a definição em (1) com as definições em (2):

(1) hijo de puta "insulto hacia una persona, haciendo referencia a la falsa condición de su madre" (GDLEe, 2001, s.v. hijo)

(2) hacia "Indica la dirección de un movimiento, físico o inmaterial, en relación con un punto al que se dirige o con un estado o un objetivo al que tiende"; "Indica la orientación física de un objeto o de una persona"; "Indica que algo está próximo de algún lugar o de algún momento en el tiempo, aunque a una distancia

tres de la tarde. Ese pueblo está hacia Tordesillas" (DRAEe, 2001, s.v. hacia, ac.2). Nesse caso, os compiladores tratam de combinar a definição em metalinguagem de conteúdo com outras técnicas de explanação do significado - mais precisamente, os exemplos -, fato que ilustra e comprova o quão difícil é lidar com essas classes de palavras. 
indeterminada"; "Con algunos verbos o nombres que expresan sentimiento o actitud, indica la persona o la cosa por la que se experimenta dicho sentimiento o ante la que se mantiene dicha actitud" (DUEAe, s.v. hacia, ac. 1, 2, 3, 4)

A definição em (1) é, de certa forma, análoga às definições em (2). Em ambos os casos, encontramo-nos, efetivamente, não com "definições" propriamente ditas, mas com "explicações". Se levamos às últimas consequências a distinção de Seco (2003), estaríamos forçosamente admitindo que a expressão hijo de puta não é definível, ou, em outros termos, é uma "expressão sem significado". Concebê-lo, no entanto, seria absurdo, pois, embora a definição seja apresentada em metalinguagem de signo, é possível apreender um “conteúdo semântico". Uma prova cabal disso é a possibilidade de definição em metalinguagem de conteúdo:

(3) hijo de puta "malsonante. Persona que actúa con mala intención y que molesta o perjudica a otros con sus faenas o malas pasadas" (DUEAe, 2003, s.v. hijo)

(4) hijo de puta "vulg. Mala persona. U. c. insulto" (DRAEe, 2001, s.v. hijo)

Em defesa do nosso ponto de vista, citamos Rey-Debove(1971, p. 172):

A metalinguagem de conteúdo é um enunciado que restitui o conteúdo do signo, SEM FALAR DO SIGNO. A metalinguagem de signo é um enunciado que fala do signo informando sobre o conteúdo do signo. [...] a metalinguagem de signo pode substituir a metalinguagem de conteúdo, mas não o contrário. $^{11}$

Dessa forma, todas as palavras poderiam ser definidas por meio de metalinguagem de signo. Rey-Debove (1971), no entanto, corroborando as palavras de Weinreich (1967), adverte que:

${ }^{11}$ No original: "La métalangue de contenu est un énoncé qui restitue le contenu du signe SANS PARLER DU SIGNE. La métalangue de signe est un énoncé qui parle du signe, éventuellement en informant sur le contenu du signe. [...] la métalangue de signe peut relayer la métalangue de contenu, mais non l'inverse". 
Trata-se, pois, de avaliar a necessidade da metalinguagem de signo, de observar se será sempre facultativa, e se não, em quais casos é obrigatória.

Começar-se-á por afirmar que é sempre possível, posto que a metalinguagem de signo está destinada especialmente ao discurso sobre os signos. Nada impede de definir esquilo como "Nome de um animal pequeno...", ou "Palavra de frequência $n$ que significa..." etc., afastando-se tanto quanto se deseje da análise do conteúdo: em última instância, tem-se uma definição de palavra como a caracterizamos [...]. Nenhuma das definições em metalinguagem de signo constitui uma análise semântica estrita; ela sempre contém outra coisa. Essencialmente uma informação sobre o emprego do signo (diz-se de, serve para, assinala etc.) e sobre a classe do signo (palavra, nome, onomatopeia etc.) [...].

A comparação das definições de $D F C$ e $P L$ demonstra-nos, por outro lado, que ela não é indispensável - isso já se sabe-, na maioria dos casos. (REY-DEBOVE, 1971, p. 249-250) ${ }^{12}$

Em uma definição como a de hijo de puta em (1), o emprego da metalinguagem de signo não é, portanto, um indício da "indefinibilidade" da palavra - nos termos que propõe Seco (2003) - tampouco um equívoco metodológico, como o mesmo autor defende. A metalinguagem de signo não somente é aceitável nesse caso, como se justifica plenamente, tendo em conta a dupla função que cumpre, ou seja, informa sobre o "significado", ou "conteúdo semântico", do signo-lema, ao mesmo tempo em que indica como se emprega. Proporciona-se, assim, ao usuário, além de uma informação estritamente semântica, também informações

${ }^{12}$ No original: "Il s'agit donc d'estimer la nécessité de la métalangue de signe, de voir si elle est toujours facultative, et si non, dans quels cas elle est obligatoire. On commencera par affirmer qu'elle est toujours possible, puisque la métalangue de signe est spécialement destinée au discours sur les signes. Rien n'empêche de définir Écureuil par «Nom d'un petit animal...», ou «Mot de fréquence $n$ qui signifie...» etc., en s'éloignant autant qu'on le veut de l'analyse du contenu: à la limite, on a une «définition de mot» telle que nous l'avons caractérisée [...]. Aucune des définitions en métalangue de signe ne constitue une stricte analyse sémantique; elle contient toujours autre chose. Essentiellement une information sur l'emploi du signe (se dit, sert à, marque etc.) et sur la classe du signe (mot, nom, onomatopée etc.) [...] La comparaison des définitions de $D F C$ et $P L$ nous montre, d'autre part, qu'elle n'est pas indispensable - ce qu'on savait déjà -, dans la majorité des cas.". 
pragmáticas. Por meio da paráfrase transcrita em (1), indica-se ao usuário: (a) a qual "extensão" - no sentido de Frege (2008) - aplica-se a "intensão" que se descreve; e (b) em que contexto se emprega a palavra/expressão definida. A metalinguagem de conteúdo, por outro lado, e como fica claro com os exemplos em (3) e (4), não permitiria fazê-lo ${ }^{13}$. Trata-se, portanto, de uma adequação da metalinguagem da definição ao tipo (ou aos tipos) de informação que se quer (ou se deve) oferecer ao usuário.

Deve-se acrescentar, ainda, que, muito embora geralmente formuladas em metalinguagem de signo, as definições das chamadas "palavras sem significado" explicitam um "conteúdo semântico" distinto em cada caso. A fim de provar nosso argumento, propomos analisar as seguintes paráfrases:

(5) Verbos auxiliares/verbos-suporte:

haberl "aux. U. para conjugar otros verbos en los tiempos compuestos.

Yo he amado Tú habrás leido" (DRAEe, 2001, s.v. haber', ac.1) echar "tr. Junto con algunos nombres, tiene la significación de los verbos que se forman de ellos o la de otros equivalentes. Echar maldiciones, maldecir; echar suertes, sortear; echar un cigarro, fumarlo; echar un sueño, dormir; echar la siesta, sestear" (DRAEe, 2001, s.v. echar, ac.25)

(6) Adjetivos/advérbios:

metrosexual "adj [Hombre] que cuida mucho de su aspecto físico, utilizando cosméticos y ropa cara. $T b n$. [...] b) Propio de (los) metrosexuales. [...]" (DEA, 2011, s.v. metrosexual)

después "adv. Expresa que la cosa de que se trata está con respecto a otra determinada más lejos en el espacio, en el tiempo o en otra circunstancia cualquiera que se considera primera o principal"; "Se emplea también con el significado de «más adelante» o «más tarde»: 'Decídete ahora; después, será tarde"”; "Con «de», se convierte en expresión prepositiva con el mismo significado: 'Mi nombre está después del tuyo en la lista""; "Puede tener un

\footnotetext{
${ }^{13}$ Em DUEAe (2003, s.v. hijo), a informação pragmática é apresentada antes da definição correspondente a hijo de puta sob a forma de marca de uso; já em DRAEe (2001, s.v. hijo), a informação pragmática é apresentada antes da definição correspondente a hijo de puta, sob a forma de marca de uso, e depois, como uma espécie de pós-comentário semântico.
} 
valor adversativo que se añade al valor temporal: 'Después de las molestias que nos ha causado, se va sin despedirse. Después de lo que me ha costado, resulta que no sirve"”; "Seguido de «que» o «de que», se convierte en expresión conjuntiva, pero sólo aplicable al tiempo: 'Después [de] que te escribí no he vuelto a verle""; "Con un nombre de tiempo antepuesto, forma locuciones adverbiales: 'Meses [días, horas, años...] después, ya nadie hablaba de ello"; " "Después que» se usaba antiguamente por «desde»: 'Después que nascí'” (DUEe, 2001, s.v. después, ac. 1, 1.1, 2, 3, 3.1, 3.2, 4, 5)

(7) Preposições/conjunções:

con "prep. Indica el contenido de una cosa: un estuche con todo tipo de maquillaje, una tarta con fresas" (DSLE, 2006, s.v. con, ac.7) de "prep. Indica la materia de la que está hecha alguna cosa: una puerta de madera, una copa de cristal" "Indica el contenido de una cosa" (DSLE, 2006, s.v. de, ac.4, 5 $)$

sin "prep. Indica falta o carencia: Estoy sin trabajo. OBSERVACIONES: Admite infinitivo y oraciones con que. En el segundo caso, puede adquirir valor aditivo, y no meramente circunstancial: El caballero salió sin que lo vieran" (DSLE, 2006, s.v. sin, ac.1)

$y^{2}$ "conj. copulat. U. para unir palabras o cláusulas en concepto afirmativo. Si se coordinan más de dos vocablos o miembros del período, solo se expresa, generalmente, antes del último. Ciudades, villas, lugares y aldeas. El mucho dormir quita el vigor al cuerpo, embota los sentidos y debilita las facultades intelectuales" (DRAEe, 2001, s.v. $y^{2}$, ac.1);

$o^{3}$ “conj. disyunt. Denota diferencia, separación o alternativa entre dos o más personas, cosas o ideas. Antonio o Francisco. Blanco o negro. Herrar o quitar el banco. Vencer o morir" (DRAEe, 2001, s.v. $o^{3}$, ac. 1 )

(8) Dêiticos:

yo "( $p l$ normal, yoes $o$ yos, en acep 4) I pron pers sg 1 Designa dentro de la frase al propio ser que la enuncia. Toma la forma de mí cuando va precedido de una de las preps comunes (excepto SEGÚN $y$, a veces, ENTRE); si la prep es Con, se une con ella formando la palabra conmigo. Toma la forma $\mathrm{ME}$ (que se pronuncia átona) cuando funciona como $\mathrm{cd}$ o ci 
sin prep; cuando va inmediatamente después del $v$, ME se escribe unido a él en una sola palabra. [...]" (DEA, 2011, s.v. yo, ac.1)

le "pron. pers. Dativo de «él, ella, ellos, ellas»: 'No les he dicho la verdad"; "Se usa generalmente en vez de «lo[s]» como acusativo del pronombre «él, ellos», cuando se refiere a personas: 'No les he visto pasar"' (DUEe, 2001, s.v. le) $a h i$ " $a d v$. lug. 1 Indica un lugar próximo tanto a la persona que habla como a la que escucha, o el lugar en que está la persona a la que se habla. OBSERVACIONES: $\diamond$ Equivale a 'a ese lugar' si va con un verbo que indique movimiento o 'en ese lugar' si va con un verbo que indique situación. $\diamond$ Admite la matización impuesta por las preposiciones desde, hasta, hacia y por: Desde ahi no se ve nada. $\diamond$ Se coloca antes que cualquier adverbio que vaya junto a él: ahi debajo, ahi delante. RELACIONES y CONTRASTES: aquí representa el lugar próximo a la persona que habla; ahí, un lugar más próximo a la persona que escucha; allí, un lugar bastante alejado." (DSLE, 2006, s.v. ahí, ac.1)

(9) Determinantes:

el "art. (Del lat. ille, aquél.) Indica el género masculino y el número singular de la palabra a la que acompaña" (GDLEe 2001: s.v. el) la “art. GRAMÁTICA (Del lat. illa, aquella.) Indica el género femenino y el número singular de la palabra a la que acompaña: pon la leche en el frigorifico y saca la mantequilla" (GDLEe 2001: s.v. la, ac.1) el "[...] art. Artículo masculino singular. [...] 1.1 Se emplea también ante sustantivos femeninos que empiezan por «a» tónica: 'el águila, el agua'." (DUEe 2001: s.v. el)

la "[...] (pronunc. átono: [lacása]) art. Se antepone a los nombres femeninos." (DUEe 2001: s.v. la, ac.1)

$m i$ "determinante posesivo Forma del determinante posesivo de primera persona del singular; indica que el nombre al que acompaña pertenece, se relaciona, está asociado, etc., con la persona que habla o escribe: ej. este es mi automóvil; mis padres viajan mucho; ya se lo preguntaré a mi profesor. NOTA El plural mis indica varios objetos poseídos, y no varios poseedores. [...]" (DUEAe 2003: s.v. mi)

Embora não sejam apresentadas "definições" propriamente ditas, mas sim "explicações", o "caráter" da explicação, por assim dizer, muda em cada caso. Isso está diretamente relacionado com a natureza/o comportamento de cada classe de palavras. 
Os verbos são, na maioria das vezes, tratados como palavras definíveis mediante metalinguagem de conteúdo (p. ex., SECO, 2003, p. 34; MARTÍNEZ DE SOUZA, 1995, s.v. definición lingüística; LANDAU, 2001, p. 173-177). Há, inclusive, trabalhos que se dedicam exclusivamente à elaboração de patterns sintáticos para as definições de verbos, levando em consideração a necessidade de expressar os chamados "contornos", que não fazem parte da definição propriamente dita e são apresentados em metalinguagem de signo (p. ex., SECO, 2003, p. 4758; CANELLADA, 1988). Entretanto, sabe-se muito pouco a respeito dos verbos que não podem ser definidos mediante metalinguagem de conteúdo, como os verbos auxiliares e os verbos-suporte, cujas definições são transcritas em (5). Os verbos auxiliares, por exemplo, na formação dos tempos compostos, apresentam tão somente uma noção gramatical, carregando as marcas morfológicas de pessoa, número, tempo e modo (BECHARA, 2006, p. 230 e ss.). A "paráfrase" apresentada no verbete correspondente ao verbo haber não contém nenhum tipo de informação semântica, mas apenas informações gramaticais. Outro tanto poderia ser dito acerca do verbo-suporte echar, cuja "paráfrase" disponibiliza informações sintáticas (colocacionais).

Em relação aos adjetivos (cf. (6)), assinalamos a necessidade de se distinguir entre qualificativos e relacionais (DEMONTE, 1999), uma vez que apenas os adjetivos pertencentes ao primeiro grupo poderiam definir-se mediante metalinguagem de conteúdo (BENEDUZI, 2008, p. 81-108). Por fim, há uma tendência a crer que os advérbios (cf. (6)) podem definir-se mediante metalinguagem de conteúdo - como é habitual entre as "palavras com significado". Seco (2003, p. 34) reconhece, entretanto, que, além das conjunções, preposições, pronomes e artigos, há certos adjetivos, verbos e advérbios aos que corresponderia uma "explicação", ou definição imprópria.

No que diz respeito à definição de preposições e conjunções (cf. (7)), propomos partir da análise dos sintagmas em (10) e das sentenças em (11):

(10) Un pan de mantequilla. / Un pan con mantequilla. / Un pan sin mantequilla.

(11) Dios es justo $y$ severo. / Dios es justo $o$ severo. / Dios es justo pero severo. / Dios es justo aunque severo.

A mera substituição da preposição/conjunção em cada contexto implica uma alteração no sentido do enunciado. Isso sugere que as 
preposições e conjunções nos exemplos apresentados "carregam" uma espécie de "conteúdo semântico", que vai além da indicação da classe à qual pertencem ${ }^{14}$. Outra prova da existência de um conteúdo semântico nesses casos é o fato de que, frequentemente, é possível encontrar "sinônimos", ou expressões semanticamente equivalentes, para preposições e conjunções (BUGUEÑO MIRANDA; FARIAS, 2011a).

A situação, no entanto, muda radicalmente no caso dos dêiticos ( $\mathrm{cf}$. (8)), bem como dos determinantes (cf. (9)): a "explicação" que se oferece ao usuário corresponde, efetivamente, à definição que lhe dá Seco (2003, p. 33), uma vez que as paráfrases não aportam informações sobre "o que significa a palavra, mas o que é essa palavra, como e para que se emprega"15.

Em relação aos dêiticos, pode-se dizer que não há um "conteúdo semântico" propriamente dito, mas tão somente uma referência que muda em cada ato de fala ${ }^{16}$. Nas definições dos pronomes yo e le em (8), é notável o fato de que não é possível formular nem mesmo uma "instrução de uso", como se propõe, por exemplo, para as conjunções e preposições (FORNARI, 2009).

Outro tanto poderia ser dito acerca dos determinantes. Particularmente em relação aos artigos, a informação apresentada em cada um dos quatro verbetes não ultrapassa os limites da classificação morfológica do signo-lema. A esse respeito, deve-se considerar, primeiramente, que as indicações fornecidas em cada caso - mesmo considerando os exemplos eventualmente subsumidos aos verbetes não refletem absolutamente a complexidade intrínseca à descrição do artigo como determinante. Bugueño Miranda (2003), ao analisar essa categoria morfológica à luz de uma gramática textual, propõe que a descrição do artigo em língua espanhola deve fundamentar-se em duas variáveis: (a) uma magnitude ôntica (apresentação de existência versus existência conhecida) e (b) uma magnitude vetorial (deslocamento prospectivo versus deslocamento retrospectivo). Em segundo lugar, e

\footnotetext{
${ }^{14}$ A existência de um "conteúdo semântico", nesses casos, torna-se ainda mais evidente, se confrontamos os exemplos de emprego das preposições de, con e sin apresentados em (10) com os casos de regência preposicional (enamorarse de, corresponder(se) a/ con), nos quais a preposição aparece completamente vazia de significado.

${ }^{15}$ No original: "qué significa la palabra, sino qué es esa palabra, cómo y para qué se emplea".

${ }^{16}$ A título de ilustração, cf. a análise que Rivarola (1991, p. 109-115) faz do pronome nosostros.
} 
em face da complexidade concernente à interpretação do artigo - que, como vimos, deve levar em conta as relações sintagmáticas estabelecidas -, indicações tão sucintas como as apresentadas em GDLEe (2001, s.v. el, s.v. la) e DUEe (2001, s.v. el, s.v. la) carecem de funcionalidade, especialmente tendo em vista o público-alvo de cada uma das obras, classificadas, respectivamente, como dicionário geral e dicionário de usos.

Confrontados com a dificuldade, ou, inclusive, a impossibilidade de oferecer uma "definição" propriamente dita, e diante da complexidade inerente à descrição linguística/lexicográfica de elementos dêiticos bem como de determinantes, os lexicógrafos optam, muitas vezes, por apresentar ao usuário um verdadeiro guia gramatical. Essa solução, embora tampouco seja ótima em todos os casos, já representa um avanço em relação, por exemplo, à descrição dos artigos em GDLEe (2001, s.v. el, s.v. la) e DUEe (2001, s.v. el, s.v. la):

(12) el, la "determinante artículo 1 Se utiliza ante nombres cuyos referentes son conocidos por el hablante o el oyente, bien porque ha sido nombrado en el discurso previo, bien porque su existencia se puede presuponer: ej. me gustó mucho el concierto; vimos a un hombre que llevaba la cabeza vendada. 2 Se utiliza ante algunos nombres propios geográficos, especialmente de mares, ríos, montañas o sierras, y también con los astros Sol y Luna: ej. los Andes son la principal arteria orográfica de América del Sur; el Ebro desemboca en el Mediterráneo. 3 Se utiliza ante nombres no contables en singular cuando desempeñan la función de sujeto de la oración: ej. me gusta el arroz. 4 Ante un nombre contable en singular, establece generalizaciones: ej. el perro es el mejor amigo del hombre; en nuestros días, la mujer ya no está relegada a las tareas domésticas. 5 Se utiliza ante nombres propios cuando tienen un complemento especificativo: ej. estas cosas no sucedían en la Europa de la posguerra; yo prefiero el Picasso de la primera época. 6 Se utiliza en plural ante apellidos para designar a todos los miembros de una familia: ej. mañana vienen a cenar los Rodríguez. 7 Se emplea delante de infinitivos para nominalizarlos y de relativos, en especial cuando puede considerarse que hay elisión de un nombre: ej. entre los métodos de separación de una mezcla podemos señalar el cribar, el filtrar, el decantar o el destilar; es para nosotros un honor el que haya aceptado nuestra 
invitación a este acto; escoge la que más te guste. 8 coloquial Se utiliza ante el nombre de pila o el apellido de una persona conocida y con la que se tiene mucha familiaridad: ej. el Pepe; la López; hace días que no veo a la María. NOTA En español cuidado es considerado un uso vulgar. [...]" (DUEAe, 2003, s.v. el, la)

Em suma, em vista das considerações feitas aqui, apenas os verbos auxiliares, os verbos-suporte, os dêiticos e os determinantes ${ }^{17}$ poderiam ser considerados "palavras indefiníveis" no sentido de Seco (2003). Utiliza-se, porém, a expressão "palavras indefiníveis" em razão da ausência de uma terminologia mais adequada; não se perde de vista, no entanto, que essa expressão está longe de ser a mais apropriada para referir-se ao fenômeno de que estamos tratando - ou seja, o fato de que algumas unidades léxicas admitam exclusivamente definições em

${ }^{17}$ No que concerne à categoria dos determinantes, deve-se fazer uma ressalva em relação aos pronomes demonstrativos e indefinidos e aos adjetivos qualificativos. No caso dos pronomes demonstrativos e indefinidos, é relativamente comum encontrá-los definidos mediante metalinguagem de conteúdo nos dicionários de língua, sem que haja prejuízo da informação em contraste com uma definição em metalinguagem de signo (cf., p. ex., a definição de otro em (13)). No caso dos adjetivos qualificativos, por outro lado, a regra é que estejam definidos mediante metalinguagem de conteúdo, de forma que uma definição em metalinguagem de signo poderia ser considerada desnecessária, ou, mesmo, inadequada (cf. as definições de maloliente, transcritas, respectivamente, em (14) e (15)):

(13) otro, otra "determinante indefinido | pronombre indefinido 1 Alguien o algo distinto, pero del mismo tipo de lo que se habla: ej he comprado uno para mí y otro para ti; no quiero el otro libro sino éste; esta película ya la he visto, ¿por qué no vamos a ver otra?; ha llegado otro que no sé quien es. 2 Alguien o algo más del mismo tipo que ciertas cosas anteriores o que se han mencionado antes: ej tendrías que comprar otra botella de vino, que con una no hay suficiente; el novelista ha publicado otro libro. 3 Alguien o algo que reúne las mismas características definitorias que alguna persona o cosa conocida que se toma como modelo: ej ese valiente soldado es otro Cid; este palacio es otro Versalles. [...]" (DUEAe, 2003, s.v. otro, otra)

(14) maloliente "adjetivo Que despide mal olor: ej transpiraba bajo la maloliente vestidura y sentía que sus propias palpitaciones acrecentaban aquel agobiante tufo; la habitación se me representaba como una escombrera, como un cubil salvaje y maloliente. [...]" (DUEAe, 2003, s.v. maloliente)

(15) maloliente "adj. Se aplica a lo que exhala mal olor [...]” (DUEe, 2001, s.v. maloliente) 
metalinguagem de signo -, uma vez que pode levar a interpretações bastante equivocadas.

\section{Considerações finais}

Levando em consideração os dois objetivos propostos na introdução deste trabalho, apresentam-se duas conclusões correspondentes. Ressalta-se que ambas as conclusões são ainda parciais, uma vez que o tema abordado, como a discussão realizada evidenciou em vários momentos, apresenta uma série de desdobramentos que merecem um tratamento mais acurado.

Do ponto de vista puramente lexicológico, não se questiona, em absoluto, a validade da distinção entre significado lexical e significado categorial, dado que, considerando as dificuldades atinentes à apreensão e definição de significado, esta distinção representa um dos poucos avanços concretos em relação à sua compreensão. Recorde-se, ainda, que a Teoria Lexemática de E. Coseriu está fundamentada na distinção significado lexical/significado categorial. Entretanto, a oposição que se deriva entre "palavras com significado" e "palavras sem significado" deve ser investigada com mais cuidado.

Do ponto de vista (meta)lexicográfico, a hipótese de existência de uma relação estrita entre "palavras com significado" e definição em metalinguagem de conteúdo, por um lado, e "palavras sem significado" e definição em metalinguagem de signo, por outro, revela-se insustentável. Há, por um lado, uma série de "expressões com significado" que exigem uma definição em metalinguagem de signo, a fim de que se possa oferecer ao consulente também indicações adicionais de natureza pragmática, ou mesmo sintática, e, por outro lado, um conjunto extenso de "expressões sem significado" para as quais é possível apresentar definições em metalinguagem de conteúdo. Trata-se, portanto, de adequar a metalinguagem da definição ao tipo de informação que deve ser veiculada pela paráfrase definidora; o tipo de informação, evidentemente, está intimamente relacionado com a natureza do significado do signolema a ser definido; esta, por sua vez, ainda está muito distante de ser apreendida e determinada em sua totalidade. 


\section{Referências}

ATKINS, B. T. S.; RUNDELL, M. The oxford guide to practical lexicography. Oxford: OUP, 2008.

BECHARA, E. Moderna gramática portuguesa. 37. ed. Rio de Janeiro: Lucerna, 2006.

BENEDUZI, R. Colocações substantivo + adjetivo: propostas para sua identificação e tratamento lexicográfico em dicionários ativos português-espanhol. 2008. 212 f. Dissertação (Mestrado em Lexicografia e Terminologia) - Instituto de Letras, UFRGS, Porto Alegre, 2008. Disponível em: <www.lume.ufrgs.br/bitstream/ handle/10183/14669/000666096.pdf>. Acesso em: 29 ago. 2014.

BORBA, F. da S. Organização de dicionários: uma introdução à lexicografia. São Paulo: UNESP, 2003.

BUGUEÑO MIRANDA, F. El artículo como determinante en una gramática del texto del español. Caligrama, Belo Horizonte, v. 8, p. 7-20, 2003. Disponível em: <http://www.periodicos.letras.ufmg.br/index.php/ caligrama/article/view/368/321>. Acesso em 29 ago. 2014.

BUGUEÑO MIRANDA, F. Para uma taxonomia de paráfrases explanatórias. Alfa, São Paulo, v. 53, n. 1, p. 243-260, 2009. Disponível em: $<$ http://seer.fclar.unesp.br/alfa/article/view/1686/1367>. Acesso em: 29 ago. 2014.

BUGUEÑO MIRANDA, F.; FARIAS, V. S. Sobre las palabras y su clasificación según su contenido. Los problemas para el lexicógrafo. Revista de Filología de la Universidad de La Laguna, La Laguna, n. 29, p. 9-19, 2011a. Disponível em: <http://publica.webs.ull.es/upload/REV\%20 FILOLOGIA/29-2011/01\%20Bugue\%C3\%B10\%20Miranda\%20y\%20 otra.pdf $>$. Acesso em: 29 ago. 2014.

BUGUEÑO MIRANDA, F.; FARIAS, V. S. Princípios para o desenvolvimento de uma teoria da definição lexicográfica. Alfa, São Paulo, v. 55, n. 1, p. 31-61, 2011b. Disponível em: <http://seer.fclar.unesp. br/alfa/article/view/4167/3765>. Acesso em: 29 ago. 2014.

BUGUEÑO MIRANDA, F.; FARIAS, V. S. Los subsidios de tres teorías semánticas para la generación de definiciones lexicográficas. Revista de Filología de la Universidad de La Laguna, La Laguna, n. 31, p. 19-34, 2013a. Disponivel em: < http://publica.webs.ull.es/upload/REV\%20 
FILOLOGIA/31-2013/Filolog\%C3\%ADa\%2031-3013.pdf>. Acesso em: 29 ago. 2014.

BUGUEÑO MIRANDA, F.; FARIAS, V. S. Teorías semánticas y definición lexicográfica: análisis de las paráfrasis explicativas de los diccionarios generales de lengua española. Cadernos de Tradução, Florianópolis, n. 32, v. 2, p. 183-225, 2013b. Disponível em: <https://periodicos.ufsc.br/ index.php/traducao/article/view/2175-7968.2013v2n32p183/25500>. Acesso em: 29 ago. 2014.

BUßMANN, H. Lexikon der Sprachwissenschaft. 4. ed. Stuttgart: Alfred Kröner, 2008.

CANELLADA, M. J. Problemas de los diccionarios. Nueva Revista de Filología Hispánica, México, v. 36, n. 1, p. 123-130, 1988. Disponível em: <http://biblio-codex.colmex.mx/exlibris/aleph/a21_1/apache_media/ G6PT2HU6376UIL7RQQT3N8XJ3N9U71.pdf >. Acesso em: 29 ago. 2014.

COSERIU, E. El estudio funcional del vocabulario (compendio de lexemática). In: COSERIU, E. Gramática, semántica, universales: estudios de lingüística funcional. Madrid: Gredos, 1978. p. 206-239.

COSERIU, E. Lo acertado y lo erróneo en las discusiones acerca de la semántica estructural en España. In: HOINKES, U. (Org.) Panorama der lexikalischen Semantik: thematische Festschrift aus Anlaß des 60. Geburtstags von Horst Geckeler. Tübingen: Narr, 1995. p. 113-124.

COSERIU, E. Criatividade e técnica linguística: os três níveis da linguagem. In: COSERIU, E. Lições de linguística geral. Trad. de Evanildo Bechara. Rio de Janeiro: Ao Livro Técnico, p. 91-100, 2004.

CRYSTAL, D. A dictionary of language. 2. ed. Chicago: The University of Chicago Press, 2001.

DEA. SECO, M.; ANDRÉS, O.; RAMOS, G. Diccionario del español actual. 2. ed. Madrid: Santillana Ediciones Generales, 2011.

DEMONTE, V. El adjetivo: Clases y usos. La posición del adjetivo en el sintagma nominal. In: BOSQUE, I.; DEMONTE, V. (eds.). Gramática descriptiva de la lengua española. Madrid: Espasa Calpe, 1999. p. 129-215. DRAEe. REAL ACADEMIA ESPAÑOLA. Diccionario de la lengua española. 22. ed. Madrid: Espasa-Calpe, 2001. Disponível em: $<$ http:// www.rae.es>. 
DSLE. GUTIÉRREZ CUADRADO, J. (dir.). Diccionario salamanca de la lengua española. Madrid: Santillana, 2006.

DUEAe. VOX. BATTANER, P. (Dir.) Diccionario de uso del español de América y España. Barcelona: SPES, 2003.

DUEe. MOLINER, M. Diccionario de uso del español. Madrid: Gredos, 2001.

FARIAS, V. S. Sobre a definição lexicográfica e seus problemas: fundamentos para uma teoria geral dos mecanismos explanatórios em dicionários semasiológicos. 2013. 399 f. Tese (Doutorado em Lexicografia e Terminologia) - Instituto de Letras, UFRGS, Porto Alegre, 2013. Disponível em: <http://www.lume.ufrgs.br/bitstream/ handle/10183/90167/000913147.pdf>. Acesso em: 29 ago. 2014.

FORNARI, M. K. O tratamento lexicográfico das palavras gramaticais: discussão teórica e análise de verbetes. Travessias, Cascavel, v. 3, n. 3, p. 167-199, 2009. Disponível em: <http://e-revista.unioeste.br/index.php/ travessias/article/view/3463/2757>. Acesso em: 15 fev. 2013.

FREGE, G. Über Sinn und Bedeutung. In: PATZIG, G. (Org.). Funktion, Begriff, Bedeutung: fünf logische Studien. Göttingen: Vandenhoeck \& Ruprecht, 2008. p. 23-46.

GDLEe. LAROUSSE. Gran diccionario de la lengua española. Barcelona: Spes, 2001.

GEERAERTS, D. The definitional practice of dictionaries and the cognitive semantic conception of polysemy. Lexicographica, Berlin, v. 17, p. 6-21, 2001.

GEERAERTS, D. Meaning and definition. In: STERKENBURG, P. van. (Ed.). A practical guide to lexicography. Amsterdam/Philadelphia: John Benjamins, 2003. p. 83-93.

GLÜCK, H. (Org.). Metzler Lexikon Sprache. 4. ed. Stuttgart: Metzler, 2010.

GREIMAS, A. J. Sémantique structurale. 3. ed. Paris: PUF, 2007.

HARTMANN, R. R. K.; JAMES, G. Dictionary of lexicography. London/ New York: Routledge, 2001.

HAUSMANN, F. J. Von der Unmöglichkeit der kontrastiven Lexikologie. In: KROMANN, H-P.; KJÆR, A. L. (Org.). Von der Allgegenwart der Lexikologie: kontrastive Lexikologie als Vorstufe zur zweisprachigen Lexikographie. Tübingen: Max Niemeyer, p. 19-23, 1995. 
HILTY, G. Lexikologie und Semantik. In: SNELL-HORNBY, M. (ed.). ZüriLEX'86 Proceedings. Papers read at the EURALEX International Congress. Tübingen: Francke Verlag, 1988. p. 3-15.

HILTY, G. Die Bedeutung von spanisch silla. In: HOINKES, U. (Org.). Panorama der lexikalischen Semantik: thematische Festschrift aus Anlaß des 60. Geburtstags von Horst Geckeler. Tübingen: Narr, 1995. p. 293-302, HILTY, G. Komponentenanalyse und Prototypensemantik. In: HOINKES, U.; DIETRICH, W. (Orgs.). Kaleidoskop der lexikalischen Semantik. Tübingen: Narr, 1997. p. 63-69.

KILGARRIFF, A. I don't believe in word senses. Computers and the Humanities, Boston, v. 31, p. 91-113, 1997. Disponível em: $<$ http://www. kilgarriff.co.uk/Publications/1997-K-CHum-believe.pdf>. Acesso em: 29 ago. 2014.

KILGARRIFF, A. Word senses. In: AGIRRE, E.; EDMONDS, P. (eds.). Word sense disambiguation: algorithms and applications. Dordrecht: Springer, 2007. p. 29-46.

LANDAU, S. Dictionaries: the art and craft of lexicography. 2. ed. Cambridge: CUP, 2001.

LUTZEIER, P. R. Linguistische Semantik. Stuttgart: Metzler, 1985.

LYONS, J. Semantics. Cambridge: CUP, 1989. V. 1.

MARTÍNEZ DE SOUZA, J. Diccionario de lexicografía práctica. Barcelona: Bibliograf, 1995.

MARTÍNEZ DE SOUZA, J. Manual básico de lexicografia. Gijón: Trea, 2009.

MATTHEWS, P. The concise oxford dictionary of linguistics. Oxford/ New York: OUP, 1997.

OGDEN, C. K.; RICHARDS, I. A. The meaning of meaning. 8. ed. New York; London: Routledge/Kegan Paul Ltd., 1956.

PALMER, F. R. Semantics. 2. ed. Cambridge: CUP, 2001.

POTTIER, B. Linguistique générale: théorie et description. Paris: Klincksieck, 1974.

PORTO DAPENA, J. A. Metalenguaje y lexicografía. Revista de Lexicografía, A Coruña, n. 6, p. 127-151, 2000. Disponível em: $<$ http:// 
ruc.udc.es/dspace/bitstream/2183/5428/1/RL_6-6.pdf > . Acesso em: 29 ago. 2014.

REY-DEBOVE, J. Étude linguistique et sémiotique des dictionnaires français contemporains. The Hague/Paris: Mouton, 1971.

REY-DEBOVE, J. La métalangue lexicographique: formes et fonctions en lexicographie monolingue. In: HAUSMANN, F. J. et al. (Orgs.). Wörterbücher, dictionaries, dictionnaires: ein internationales Handbuch zur Lexikographie. Berlin/New York: Walter de Gruyter, 1989. V. 1, p. 305-312. RIVAROLA, J. L. Signos y significados: ensayos de semántica lingüística. Lima: Pontificia Universidad Católica del Perú/Fondo Editorial, 1991.

SCHIFKO, P. Lexicología y semántica. In: HOLTUS, G.; METZELTIN, M.; SCHMITT, C. (Orgs.). Lexikon der romanistischen Linguistik. Tübingen: Max Niemeyer, 1992. V. 6/1. p. 132-148.

SECO, M. Estudios de lexicografía española. 2. ed. Madrid: Gredos, 2003.

SINCLAIR, J. Meaning in the framework of corpus linguistics. Lexicographica, Berlin, v. 20, p. 20-32, 2004.

ULLMANN, S. Semantics: an introduction to the science of meaning. Oxford: Basil Blackwell, 1964.

ULRICH, W. Wörterbuch linguistischer Begriffe. 5. ed. Berlin/Stuttgart: Gebrüder Borntraeger, 2002.

WEINREICH, U. Lexicographic definition in descriptive semantics. In: HOUSEHOLDER, F.W.; SAPORTA, S. Problems in lexicography. Bloomington: Indiana University/Mouton \& Co., 1967. p. 25-44.

ZGUSTA, L. Manual of lexicography. Prague/Paris: Academia/Mouton, 1971. 
